JURISPRUDENCIA 
Revista de Derecho

\title{
Análisis de la sentencia en el caso La última tentación de Cristo (Olmedo Bustos y otros vs. Chile) de la Corte Interamericana de Derechos Humanos*
}

\author{
Analysis of the judgment of the Case of The Last \\ Temptation of Christ (Olmedo Bustos et al.) vs. Chile of \\ the Inter-American Human Rights Court
}

Elena Fernández Torres

Universidad UTE (Santo Domingo)

elena.fernandez@ute.edu.ec

DOI: https://doi.org/10.32719/26312484.2019.31.9

Fecha de recepción: 2 de abril de 2018

Fecha de aprobación: 26 de febrero de 2019

Licencia Creative Commons

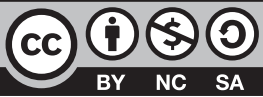

* Corte Interamericana de Derechos Humanos, "Sentencia de 5 de febrero de 2001 (Fondo, Reparaciones y Costas)", Caso "La Última Tentación de Cristo" (Olmedo Bustos y otros) vs. Chile, 5 de febrero de 2001, 〈http://www.corteidh.or.cr/docs/casos/articulos/Seriec_73_esp.pdf〉. 


\section{RESUMEN}

En este fallo judicial la Corte Interamericana de Derechos Humanos examina la posible vulneración de los derechos de libertad de pensamiento y expresión, en contraste con los de conciencia y religión, ante la imposición de censura judicial para la comunicación pública y divulgación de la película La última tentación de Cristo. ${ }^{1}$ Asimismo, analiza la obligación del Estado de Chile de respetar los derechos y deberes establecidos en la Convención Americana sobre Derechos Humanos $^{2}$ relativos a las libertades públicas ya mentadas y, en consecuencia, la responsabilidad objetiva del Estado. En esta dirección, interesa en el presente análisis ahondar desde la teoría crítica en la tensión entre el derecho formal, como expresión del poder, y el arte, desde la dimensión política y axiológica del derecho; ${ }^{3}$ finalmente, se reflexiona sobre la eficacia de la resolución judicial internacional.

PALABRAS CLAVE: libertad de pensamiento y expresión, libertad artística, libertad de consciencia y religión, derecho al honor.

\section{ABSTRACT}

The Inter-American Court of Human Rights analyzes about the possible infringement of the freedoms of thought and expression in contrast with freedoms of conscience and religious, against the judicial censure enforcement for the communication and outreach of "The Last Temptation of Christ". In addition, it analyzed the obligation of respect from the Chilean Estate, in order to enforce the rights and duties from The American Convention on Human Rights, about those rights and the state responsibility. According to this, we are interested in deepen from the Critical Theory into the tension between Formal Law -as a power manifestationand Art, from the political and axiological Law dimension. Finally, this text thinks over the effectiveness of the judgment.

KEYWORDS: Freedoms of thought and expression, artistic freedom, freedoms of conscience and religious, right to honor or reputation.

1. Martin Scorsese, The Last Temptation of Christ, DVD (EE. UU.: Cineplex Odeon Films, 1988).

2. OEA, Convención Americana sobre Derechos Humanos (Pacto de San José de Costa Rica), 22 de noviembre de 1969.

3. Julio Fernández Bulté, Teoría del Derecho (La Habana: Félix Varela, 2004). 


\section{ANTECEDENTES}

$\mathrm{C}$ omo consecuencia del artículo 19.12 de la Constitución Política de Chile de 1980 existía un sistema de censura de productos cinematográficos, que produjo que en los años 1988 y 1996 el Consejo de Calificación Cinematográfico chileno denegara la solicitud de autorización para comunicar y divulgar públicamente la obra cinematográfica La última tentación de Cristo en ese país, por la compañía United International Pictures Ltda.

En la primera ocasión dicha solicitud no prosperó en vía administrativa ni judicial. ${ }^{4}$ En el segundo caso, el órgano competente accedió a la petición, autorizándose en esta ocasión solo para mayores de 18 años. Dicha resolución administrativa esta vez fue combatida por un recurso de protección interpuesto por representantes legales de la Iglesia católica, a nombre de Jesucristo, ante la Corte de Apelaciones de Santiago de Chile. La Corte acogió el recurso dejando sin efectos la resolución administrativa. Esta sentencia de apelaciones fue interpelada por nuevos demandantes ante la Corte Suprema de Justicia de Chile, la que falló confirmando la sentencia cuestionada. De este modo quedó sentado el criterio del Poder Judicial de censurar la exhibición de la obra cinematográfica de referencia. ${ }^{5}$

Los demandantes afectados acudieron ante el Sistema Interamericano de Derechos Humanos, demandando al Estado de Chile ante la presunta violación de los derechos de libertad de pensamiento y expresión, de conciencia y religión, y ante el incumplimiento de las obligaciones de respetar los derechos y el deber de adoptar disposiciones de derecho interno. ${ }^{6}$ Sus pretensiones contra el Estado de Chile fueron en consecuencia las siguientes:

1. Autorizar la normal exhibición cinematográfica y publicidad de la película La última tentación de Cristo.

2. Adecuar sus normas constitucionales y legales a los estándares sobre libertad de expresión consagrados en la Convención Americana, a fin de eliminar la censura previa a las producciones cinematográficas y su publicidad.

3. Asegurar que los órganos del poder público y sus autoridades y funcionarios en el ejercicio de sus diferentes potestades, ejerzan estas de manera de hacer efectivos los derechos y libertades de expresión, conciencia y religión reconocidos en la Convención

4. Corte IDH, "Sentencia de 5 de febrero de 2001", párr. 60.

5. Ibíd.

6. Fueron invocados los siguientes fundamentos legales: OEA, Convención Americana de los Derechos Humanos, art. 1.1, 2, 12, 13, 50 y 51; CIDH, Reglamento de la Comisión Interamericana de Derechos Humanos, 1 de agosto de 2013. 
Americana, y en consecuencia se abstengan de imponer censura previa a las producciones cinematográficas.

4. Reparar a las víctimas en este caso por el daño sufrido.

5. Efectuar el pago de costas y reembolsar los gastos incurridos por las víctimas [...].

De este modo inició el proceso judicial en la Corte Interamericana que concluyó con la sentencia de fecha 5 de febrero de 2001. Sobre el procedimiento en cuestión vale solo señalar determinados elementos relevantes. Entre ellos, el Estado de Chile contestó de forma extemporánea la demanda, así declarado por la Corte; en consecuencia, no presentó prueba alguna. Por su parte, la Comisión aportó pruebas documentales (entre estas el libro La última tentación, de Nikos Kazantzakis), ${ }^{8}$ así como todos aquellos encaminados a probar los perjuicios sufridos por las víctimas -en cuanto a su cuantificación concreta-. Se practicaron pruebas de testigos (dos), se aportaron dictámenes de tres peritos (solicitados por la Comisión), y otros dos (requeridos de oficio por la Corte). ${ }^{9}$ Una vez practicadas las pruebas, encontrándose en la fase del proceso en la que las partes debían aportar sus informes finales, con prórrogas otorgadas, el Estado de Chile, en fecha 22 de enero de 2001, aportó a la Corte un proyecto de reforma constitucional que cesaba la censura cinematográfica en cuestión. ${ }^{10}$

En relación al proyecto de reforma constitucional, es necesario explicar que fue propuesto por el presidente de la República en el año 1997, con el fin de modificar la legislación nacional referente a la censura de obras cinematográficas y, en consecuencia, sustituirla por un sistema de calificación de "libre creación artística". Dicho proyecto fue aprobado por la Cámara de Diputados en 1999. Sin embargo, hasta la fecha en la que fue dictada la sentencia objeto de análisis, no había sido implementado ningún mecanismo que apuntara hacia la promulgación y efectiva instauración de dicha reforma. ${ }^{11}$

7. Corte IDH, "Sentencia de 5 de febrero de 2001", párr. 91.

8. Nikos Kazantzakis, The Last Temptation of Christ (EE. UU.: Simon \& Schuster \& Bruno Cassirer, 1955).

9. Corte IDH, "Sentencia de 5 de febrero de 2001", párr. 42-45.

10. Ibíd., párr. 39.

11. Ibíd. El sistema nacional que legitimaba la "censura cinematográfica" estaba regulado para la época en la Constitución Política de Chile de 1980, así como otras normas de jerarquía normativa inferior, estableciendo así el sistema de calificación de obras cinematográficas. En este sentido, ver Chile, Constitución Política de la República de Chile, Decreto Supremo 1150 del Ministerio del Interior, 21 de octubre de 1980, art. 19, núm. 12; Chile, Decreto Ley 679, Normas sobre calificación cinematográfica, 10 de octubre de 1974, derogado en fecha 4 de enero de 2003; Chile, Decreto 18, Reglamento sobre calificación de la producción cinematográfica, 11 de julio de 2003. 


\section{ANÁLISIS DE FONDO}

Una vez relatadas las cuestiones procedimentales, así como establecida la pretensión de la parte demandada, nos encontramos en condiciones de poder analizar la vulneración de los derechos denunciados, así como el incumplimiento del Estado de Chile de las obligaciones y deberes contraídos como parte de la Convención. Asimismo, del posible daño moral y material, los perjuicios generados por la censura de exhibición de la obra cinematográfica, y la consecuente reparación.

\section{LOS DERECHOS HUMANOS RELATIVOS A LA DIGNIDAD DE LA PERSONA (DERECHO AL HONOR) VERSUS LAS LIBERTADES PÚBLICAS (DE PENSAMIENTO Y EXPRESIÓN, Y DE CONCIENCIA Y RELIGIÓN)}

Los derechos humanos son inherentes a toda persona, indisolublemente ligados a su dignidad misma, y, en consecuencia, se expresan como atributos de la personalidad jurídica desde el mismo momento en que los seres humanos ya somos considerados personas. ${ }^{12}$ Asimismo, son considerados derechos preexistentes, según Javier Hervada "independientes de la ley positiva y del consenso social". ${ }^{13}$

La protección de estos derechos se ha convertido en un principio general a su vez del Derecho internacional, pero también parte integrante e inseparable del derecho público. ${ }^{14}$ En consecuencia, se observa la necesidad de protección en los Estados nacionales, y en sus constituciones, pero desde un punto de vista humanista, considerando a cada ser humano como persona, sujeto de derecho internacional y nacional. Todo ello lleva consigo la obligatoriedad de los Estados de proteger y promover dichos derechos. ${ }^{15}$ Dicho en palabras de Peña Torres:

12. Javier Hervada, "Problemas que una nota esencial de los derechos humanos plantea a la filosofía del derecho", Persona y Derecho, n. 9 (1982): 243-56, 〈http://hdl.handle.net/10171/12040〉.

13. Hervada, "Problemas que una nota esencial de los derechos humanos plantea", 255-6.

14. Germán Bidart Campos, "La interpretación de los derechos humanos en la jurisdicción internacional y en la jurisdicción interna", en La Corte y el Sistema Interamericano de Derechos Humanos: edición conmemorativa de los quince años de la instalación de la Corte Interamericana de Derechos Humanos, de los veinticinco de la firma del Pacto de San José de Costa Rica y de los treinta y cinco de la creación de la Comisión Interamericana de Derechos Humanos, ed. por Corte Interamericana de Derechos Humanos (San José: Corte Interamericana de Derechos Humanos, 1994), 39-52.

15. Germán Bidart Campos, "La interpretación de los derechos humanos en la jurisdicción internacional y en la jurisdicción interna”, 96. 
la libertad, la justicia y la paz en el mundo tienen por base el reconocimiento de la dignidad intrínseca, y de los derechos iguales e inalienables de todos los miembros de la familia humana [...] los Estados miembros se han comprometido a asegurar, en cooperación con la Organización de las Naciones Unidas, el respeto universal y efectivo a los derechos y libertades fundamentales del hombre. ${ }^{16}$

Los derechos humanos a su vez suelen ser regulados también bajo el rubro de derechos fundamentales, que si bien parten de los derechos humanos en cuanto al alcance de su protección y su contenido, propiamente distan de ser lo mismo. Estos derechos se desarrollan en el marco del derecho constitucional, siendo en sí la regulación y legitimación de los derechos humanos en los ordenamientos jurídicos nacionales a partir de su positivización en las constituciones. A tales fines queda regulado su reconocimiento, imponiendo ciertos límites a las libertades individuales que pudiesen vulnerar los mismos. ${ }^{17}$

En cuanto a las libertades públicas, se trata de facultades de ejercer ciertas actividades sin interferencias estatales, otorgadas a los particulares o grupos sociales, que en algunos casos coinciden con ciertos derechos humanos, y también podrían coincidir con derechos fundamentales. ${ }^{18}$

Por último, los derechos de la personalidad son aquellos que se enfocan en su esfera más personal de protección, una vez que han sido garantizados sus derechos frente al Estado. Su forma de protección también los distingue, pues estos pueden no solo estar protegidos constitucionalmente, sino también desde el ámbito penal y administrativo, pero también desde el Derecho civil, cuando esos son vulnerados por otra persona, en especial cuando se atenta contra los derechos inherentes a la personalidad. ${ }^{19}$ Son derechos inseparables de la condición humana, irrenunciables, y que se desarrollan en el ámbito social de la persona, a diferencia de los otros derechos o libertades que se desarrollan en el ámbito público y ajeno de su propia personalidad. ${ }^{20}$

El objeto de estos derechos son los bienes fundamentales de la persona, derivados de su dignidad, que requieren ser protegidos de forma unitaria, pues cualquier aspecto de la personalidad podría ser lesionada y por consiguiente requerirá igualmente protección en su integridad. ${ }^{21}$

16. Marisol Peña Torres, "La aplicación del Derecho Internacional de los Derechos Humanos por el Tribunal Constitucional Chileno", Estudios Constitucionales 8, n. ${ }^{\circ} 1$ (2010): 426, 〈http://www.estudiosconstitucionales.cl/index.php/econstitucionales〉.

17. Ana María Álvarez Tabío, "Los derechos inherentes a la personalidad", Boletín ONBC, n. ${ }^{\circ} 16$ (2004): 20.

18. Álvarez Tabío, "Los derechos inherentes a la personalidad", 20.

19. Ibíd., 22-3.

20. Ibíd., 23.

21. Ibíd., 42. 
Justamente dentro de los derechos inherentes a la personalidad, en especial dentro de su contenido moral, encontramos el derecho al honor, la intimidad, la propia imagen, y las libertades de expresión y de información. ${ }^{22}$ Según De Cossio, se trata de bienes que se encuentran contenidos en el patrimonio moral de la persona, como bienes jurídicos. ${ }^{23}$ Aunque estos derechos son contemplados por un sector de la doctrina desde su aspecto manifiesto en la esfera moral, estos no niegan su contenido patrimonial en cuanto a los efectos que pueden producirse en materia de daños y estimaciones pecuniarias, ${ }^{24}$ sobre todo en temas de daños. El derecho al honor, por su parte, es también identificado como el derecho a la reputación. ${ }^{25}$ Pero también se observa ligado estrechamente a los derechos anteriores. ${ }^{26}$

Su relación con los derechos de libertad de expresión y derecho a la información se conforma a partir de la interacción que estos derechos tienen, al momento en que el ejercicio de estas libertades no debe afectar el honor en base a la divulgación de hechos falsos, injuriosos, descalificatorios ${ }^{27} \mathrm{o}$ expresiones difamatorias, de carácter sexista, racista, xenófobo $u$ otros ${ }^{28}$ que en efecto puedan causar un daño probado en el orden moral o patrimonial. En consecuencia, esta relación se establece a partir de límites en el ejercicio de las libertades públicas para la protección de la esfera más íntima de la persona. Pero también el derecho al honor puede ser observado como un límite a la libertad de expresión, de acceso a la información, y dentro del primero, de la libertad artística, sobre todo cuando su interés se desborda al ámbito público, en cuyo caso queda ponderar qué derecho es más importante proteger, y justamente el caso en estudio observa esta tensión.

Por su parte, el derecho a la libertad de conciencia y religión viene dado como un derecho de corte social y político, que protege justamente el respeto por la libre elección de ideología o creencias, de forma que el ciudadano queda protegido frente al Estado y frente a terceros. Su ejercicio estaría limitado obviamente por cuestiones de orden público, de seguridad colectiva, o del respeto por las libertades públicas de terceros, de modo que su fin siempre tiene que ser lícito y, en consecuencia, dentro de los límites razonables en sociedades democráticas. ${ }^{29}$ Es un derecho que ha sido

22. Ibíd., 51.

23. Manuel de Cossío, Derecho al honor: técnicas y límites (Valencia: Tirant Lo Blanch, 1993), 39-49.

24. Álvarez Tabío, "Los derechos inherentes a la personalidad".

25. Ernesto Gutiérrez y González, El patrimonio: el pecuniario y el moral o derechos de la personalidad y derecho sucesorio, 3. ${ }^{a}$ ed. (México D. F.: Editorial Porrúa, 1990), 762.

26. Álvarez Tabío, "Los derechos inherentes a la personalidad".

27. Ibíd., 101.

28. Ibíd., 57 y 102.

29. ONU Asamblea General, Declaración sobre la eliminación de todas las formas de intolerancia y discri- 
protegido por varios instrumentos jurídicos internacionales, y también cumple un fin histórico en pos de proteger a los ciudadanos frente a persecuciones religiosas que puedan poner en riesgo su integridad física, moral o su propia vida. ${ }^{30}$

Entendido y sentado un marco referencial doctrinal, podemos observar esta tensión entre el derecho al honor y las libertades públicas referidas en el caso en examen.

En este sentido, la libertad de pensamiento y expresión se encuentra regulada en el artículo 13 de la Convención, cuyo alcance comprende el derecho al acceso a la información. Asimismo, este derecho no puede ser objeto de censura, sino, como establece la propia Convención, a responsabilidades ulteriores que contemplan en numerus clausus específicamente "el respeto a los derechos o la reputación de los demás [y] la protección de la seguridad nacional, el orden público, la salud o la moral públicas". ${ }^{31}$

Tampoco puede restringirse por medios indirectos que impliquen abuso de poder a través de medios de difusión masiva. Queda establecida como excepción de censura "la protección de la moral de la infancia y la adolescencia", ${ }^{32}$ y finalmente regula la Convención que prohibe "toda propaganda a favor de la guerra, apología de odio nacional, racial o religiosa $[\ldots]$ "..33

En la sentencia de referencia, la Corte indica que el derecho a la libertad de pensamiento y expresión debe considerarse en su doble dimensión: individual y social. La primera contempla el acceso a la información, pero también a hablar, escribir, difundir su pensamiento, de modo que "una restricción de las posibilidades de divulgación representa directamente un límite al derecho de expresarse libremente". ${ }^{34}$ En relación a la dimensión social comprende "el derecho de comunicar a otros sus puntos de vista, pero también implica el derecho de todos a conocer opiniones, relatos y noticias". ${ }^{35}$ Para la Corte, ambas dimensiones poseen igual importancia, y por ello considera este derecho como base fundamental de una sociedad democrática. ${ }^{36}$

minación, el derecho a la libertad de pensamiento, conciencia, religión o convicciones, 25 de noviembre de $1981, \mathrm{R} / 36 / 55$.

30. Dentro de los instrumentos jurídicos internacionales más relevantes se encuentran los siguientes: ONU Asamblea General, Declaración Universal de los Derechos Humanos, 10 de diciembre de 1948, R/217/1/ III; OEA, Declaración Americana de los Derechos y Deberes del Hombre, 1948; ONU Asamblea General, Pacto Internacional de Derechos Económicos, Sociales y Culturales, 16 de diciembre de 1966, R/2200/A/ XXI; y la anteriormente referida Declaración sobre la eliminación de todas las formas de intolerancia y discriminación fundadas en la religión o las convicciones.

31. Corte IDH, "Sentencia de 5 de febrero de 2001", párr. 63.

32. Ibíd.

33. Ibíd.

34. Ibíd., párr. 65 .

35. Ibíd., párr. 66 .

36. Ibíd., párr. 68 . 
Por otra parte, de los hechos probados, y aceptados asimismo por el Estado de Chile, se pudo comprobar que en ese país al momento de dictarse el fallo judicial en análisis, existía un sistema de censura previa para la exhibición y publicidad de la producción cinematográfica, con un aparataje administrativo representado por el Consejo de Calificación Cinematográfica, como vimos anteriormente. Del análisis de las actuaciones administrativas y judiciales en Chile, la Corte concluyó que en efecto hubo una censura previa impuesta en violación al artículo 13 de la Convención.

En relación al derecho a la libertad de conciencia y religión, previsto en el artículo 12 de la Convención, la Comisión alegó que dicho artículo fue violado el momento en que fue prohibida la comunicación pública y divulgación de una obra con contenido religioso, mientras que el Estado opinó que "no se violó el derecho de las personas a conservar, cambiar, profesar y divulgar sus religiones o creencias". ${ }^{37}$ En este sentido, la Corte falló declarando que la libertad de religión y conciencia es un cimiento de toda sociedad democrática; sin embargo, no existió tal violación considerando que la privación o menoscabo del referido derecho de ninguna persona no fue probado debidamente por la parte demandante. ${ }^{38}$

De este modo, quedaron zanjados dos importantes puntos contenidos en la pretensión de la demanda. La Corte en ambos casos ponderó las libertades públicas por encima del derecho al honor y la reputación (en este caso de Jesucristo). Consideró estos derechos como fundacionales y esenciales en una sociedad democrática; por consiguiente, se entiende que la libertad artística estaría comprendida dentro del contenido de la libertad de expresión como derecho a compartir y divulgar las propias ideas y pensamientos.

\section{Eficacia de los tratados de derechos humanos}

\section{en el Caso La Última tentación de CRISTo}

En este sentido, la Corte falló sobre la posible vulneración en específico de los artículos 1.1. y 2 de la Convención (obligaciones de respetar y garantizar). En primer lugar, se aclaró que el deber general del Estado como miembro de este tratado internacional, en virtud del mentado artículo 2, sería de respetar el contenido mismo del instrumento jurídico, pero también el deber de adoptar todas las medidas necesarias para armonizar el derecho interno a estas disposiciones, lo que incluye la eliminación

37. Corte IDH, "Sentencia de 5 de febrero de 2001", párr. 77.

38. Ibíd., párr. 103 . 
de todas las normas que violen e incumplan los derechos y garantías contenidos en la Convención, de modo que la misma pueda ser totalmente eficaz.

Siguiendo esta dirección, la Corte determinó que el Estado de Chile violó los derechos contenidos en el artículo 13 de la Convención de los demandantes; en consecuencia, incumplió el deber de respetar los derechos y libertades contenidos en la misma, y su pleno ejercicio conforme lo establecido en su artículo 1.1.

En el caso de estudio, la censura de exhibición de la obra cinematográfica La última tentación de Cristo en Chile, amparada en la legislación nacional, el Estado incumplió las disposiciones de la Convención establecidas en los artículos 1.1 y 2. Si bien es cierto que al momento de dictarse la sentencia examinada existía un proyecto de reforma aportado por el Estado de Chile, encaminado a eliminar la censura cinematográfica y, en consecuencia, de respetar y reestablecer los derechos vulnerados de libertad de pensamiento y expresión, este proyecto aprobado en 1999 todavía no había sido promulgado, ni se habían implementado medidas internas para hacer efectiva y válida su aplicación. De este modo, se mantenían vivas las comentadas violaciones.

En relación al artículo 63.1 de la Convención, relativo al reconocimiento del daño y su reparación, la Corte estimó que la sentencia por sí misma ya era una forma de reparación moral a las víctimas (comprendiendo en este sentido su contenido moral, a partir de una declaración pública). En su aspecto patrimonial, también dispuso una reparación pecuniaria relativa al reembolso de los gastos por las gestiones realizadas por las víctimas ante los órganos jurisdiccionales correspondientes, tanto internos como ante la Corte Interamericana, en base al principio de equidad. De modo que el Estado de Chile $^{39}$ quedó obligado a resarcir a las víctimas en los montos establecidos por la Corte. ${ }^{40}$

\section{FALlo JUdiCIAL INTERAMERICANO: MIRADA CRÍTICA}

\section{DE LA TENSIÓN ENTRE EL DERECHO FORMAL Y EL ARTE}

Consideramos que el fallo de la Corte no solo reconoció la violación de derechos en cuanto al derecho humano de libertad de pensamiento y expresión, y del incumplimiento por parte del Estado de Chile de los deberes y garantías contenidos en la

39. Corte IDH, "Sentencia de 5 de febrero de 2001", párr. 17, 19 y 21. Es de recordar que el Estado adquiere una responsabilidad internacional por cualquier acción u omisión de cualquier órgano o poder de forma indivisible, aun cuando estos se basen en el principio de independencia y jerarquía.

40. Ibíd., párr. 103, punto 5 . 
Convención en el derecho interno, sino que sentó un precedente jurisprudencial en materia de la libertad de expresión.

Como bien se expresó en la sentencia, la libertad de expresión en su concepción amplia abarca el derecho a la información y a divulgar las propias ideas y pensamientos. En este sentido, la libertad artística es una manifestación de este derecho. En consecuencia, advertimos con este caso una tensión entre las normas de derecho formal y el arte. La coacción, restricción y limitación del arte -a través de la censura de exhibición de la obra cinematográfica en cuestión-, nos muestra una nueva mirada desde la teoría crítica, desde esta lucha de poder en este caso por la autoexpresión. Según Bourdieu, tanto el arte como el derecho se encuentran contenidos en campos de poder que se organizan y estructuran a partir de normas, reglas específicas para cada uno de estos, y, asimismo, luchas de poder al interior de cada campo donde se distribuyen y acumulan capitales específicos. ${ }^{41}$

Al interior de los campos, se rigen a través de lo que Bourdieu llama el habitus, entendiéndose como un sistema de disposiciones que se transfiere y que conforma estructuras que generan prácticas y representaciones, bajo determinados fines que no necesariamente obedecen a reglas fijas. En consecuencia, el mundo de la práctica se constituye en relación con el habitus, con un espacio social con fines ya cumplidos o realizados, generando patrones, percepciones, experiencias y libertad de pensamiento donde se produce.

El rol del Estado en estos juegos de poder se impone sobre los conflictos como una especie de árbitro o clarificador, y concentra o mantiene el monopolio de la violencia legítima, aunque no lo logra de forma absoluta. ${ }^{42}$ De modo que tanto el derecho formal como el arte en el caso en concreto sostuvieron cierta tensión sobre qué contenidos o ideas, pensamientos pueden ser divulgados y son legítimos para comunicar públicamente.

El arte marginado por la ponderación al derecho al honor y la reputación de Jesucristo y, en consecuencia, el acceso a la información y a la autoexpresión no solo de los demandantes, sino del pueblo chileno. El arte se entendería desde aquí como un método discursivo de poder para denunciar, decir, divulgar ideas, emociones, pensamientos, y en este sentido, se convierte en una forma de validar el sistema democrático de derechos. Convierte al sistema de derecho en un principio de justicia altamente

41. Pierre Bourdieu, "Algunas propiedades de los campos", en Cuestiones de Sociología (Madrid: Akal, 2008), 112-9.

42. Pierre Bourdieu, "Estructuras, hábitos y prácticas", en El sentido práctico (Buenos Aires: Siglo XXI Editores, 2007), 85-105. 
formal donde se desvirtúa el sentido e ideal de justicia como un principio axiológico de difícil concreción, y conduce a una crisis de legitimación del derecho interno. ${ }^{43}$

\section{EFECTOS EJECUTIVos del FALLO JUdicial}

El Estado de Chile fue coactado en cuatro ocasiones por la Corte para dar cumplimiento a la sentencia a solicitud de la Comisión y las víctimas. Las observaciones de las víctimas a estos informes denunciaron que no se había levantado la censura sobre la exhibición de la película La última tentación de Cristo, ni promulgado las nuevas reformas al ordenamiento jurídico, debido a dilaciones excesivas en su aprobación agravando los perjuicios y privándolos de una efectiva y oportuna tutela de sus derechos. ${ }^{44}$

En este sentido, el 28 de noviembre de 2002 la Corte dictó una nueva resolución de cumplimiento de sentencia ${ }^{45}$ en la que se resuelve disponer nuevamente la obligación del Estado de Chile en la adopción de todas las medidas necesarias para dar cumplimiento total a la sentencia de fecha 5 de febrero de 2001, conforme lo regulado en la Convención. Se dispuso un nuevo término para que se presentase informe detallado de las nuevas gestiones. Asimismo, se otorgó un plazo a las víctimas y la Comisión para presentar sus observaciones sobre el Informe del Estado y su cumplimiento. ${ }^{46}$

Actualmente la sentencia se encuentra completamente cumplida, y desde el 9 de enero de 2003 la película La última tentación de Cristo fue recalificada y aprobada para su exhibición para mayores de 18 años. Sin embargo, resalta todo el tiempo y esfuerzo que la ejecución implicó para las víctimas, así como la agravación consecuente de los perjuicios sufridos. ${ }^{47}$

\section{CONCLUSIONES}

El caso de censura de La última tentación de Cristo muestra tensiones evidentes en el control del poder y en un contexto de transición de una férrea dictadura a un sistema democrático en el Estado de Chile.

43. Pierre Bourdieu, "Espacio social y poder simbólico", en Cosas dichas (México D. F.: Gedisa, 2000), 127-42.

44. Corte IDH, Resolución (de supervisión de cumplimiento de sentencia), Caso La última tentación de Cristo (Olmedo Bustos y otros), 28 de noviembre de 2002.

45. Ibíd.

46. Ibíd.

47. Corte IDH, Resolución (de supervisión de cumplimiento de sentencia), Caso La última tentación de Cristo (Olmedo Bustos y otros), 28 de noviembre de 2003. 
La censura a la obra cinematográfica fue promovida al considerarse dañado el derecho al honor y la reputación de Jesucristo, debido al contenido religioso de la película dirigida por Martin Scorserse. En este sentido, pudimos apreciar una ponderación en la jurisprudencia nacional de este derecho por encima del derecho a la libertad de pensamiento y expresión.

En relación al incumplimiento del Estado de Chile de las libertades y garantías contenidas en la Convención, se observa una cuestión de incompatibilidad de normas, en este caso una de derecho interno y la otra de derecho internacional. Los criterios jurisprudenciales a posteriori afirman que en estos casos siempre debe considerarse como criterio más elevado la existencia de las víctimas y del daño; en consecuencia, considerándolo como una violación de derechos humanos en forma concreta y de aplicación directa de la Convención. Asimismo, se manejan los criterios de responsabilidad internacional objetiva, donde se debe valorar el deber de prevención del Estado como miembro de la Convención. ${ }^{48}$

Resaltamos como relevante la consideración de que la responsabilidad del Estado es unitaria e indivisible, aunque en lo interno el ordenamiento jurídico se despliegue alrededor del principio de independencia de poderes. Ante incumplimientos de derechos humanos, existencia de víctimas y afectaciones concretas, el Estado es responsable por todos y cada uno de sus órganos de poder.

Finalmente, se recomienda el examen de la referida sentencia como un caso jurisprudencial vital sobre la ponderación de derechos inherentes a la personalidad, como el honor, y libertades públicas, así como pugnas de poder en torno al derecho y el arte, y finalmente, en cuanto a la protección internacional de derechos humanos, en especial el derecho a la libertad de pensamiento y expresión.

\section{BIBLIOGRAFÍA}

Álvarez Tabío, Ana María. "Los derechos inherentes a la personalidad”. Boletín ONBC, n. ${ }^{\circ} 16$ (2004): 1-67.

Bidart Campos, Germán. "La interpretación de los derechos humanos en la jurisdicción internacional y en la jurisdicción interna". En La Corte y el Sistema Interamericano de Derechos Humanos: Edición conmemorativa de los quince años de la instalación de la Corte Interamericana de Derechos Humanos, de los veinticinco de la firma del Pacto de San José de Costa Rica y de los treinta y cinco de la creación de la Comisión Interamericana de Derechos Humanos, editado por la Corte Interamericana de Derechos Humanos, 39-52. San José: Corte Interamericana de Derechos Humanos, 1994.

48. Ver en este sentido el voto concurrente del juez A. A. Cancado Trindade. 
Chile. Constitución Política de la República de Chile. Decreto Supremo 1150 del Ministerio del Interior. 21 de octubre de 1980.

- Decreto 18, Reglamento sobre calificación de la producción cinematográfica. 11 de julio de 2003.

- Decreto Ley 679, Normas sobre calificación cinematográfica. 10 de octubre de 1974.

Comisión Interamericana de Derechos Humanos. Reglamento de la Comisión Interamericana de Derechos Humanos. 1 de agosto de 2013.

Corte Interamericana de Derechos Humanos. "Sentencia de 5 de febrero de 2001 (Fondo, Reparaciones y Costas)". Caso "La última tentación de Cristo" (Olmedo Bustos y otros) vs. Chile. 5 de febrero de 2001, 〈http://www. corteidh.or.cr/docs/casos/articulos/Seriec_73 esp.pdf .

De Cossio, Manuel. Derecho al honor: Técnicas y límites. Valencia: Tirant lo Blanch, 1993.

Fernández Bulté, Julio. Teoría del Derecho. La Habana: Félix Varela, 2004.

Gutiérrez y González, Ernesto. El patrimonio: el pecuniario y el moral o derechos de la personalidad y derecho sucesorio, 3. a ed. México D. F.: Porrúa, 1990.

Hervada, J. Javier. "Problemas que una nota esencial de los derechos humanos plantea a la filosofía del derecho". Persona y Derecho, n. 9 (1982): 243-56. 〈http://hdl.handle. net/10171/12040>.

Kazantzakis, Nikos. The Last Temptation of Christ. EE. UU.: Simon \& Schuster \& Bruno Cassirer, 1955.

OEA Secretario General. Convención Americana sobre Derechos Humanos (Pacto de San José de Costa Rica). 22 de noviembre de 1969.

—. Declaración Americana de los Derechos y Deberes del Hombre. 1948.

ONU Asamblea General. Declaración sobre la eliminación de todas las formas de intolerancia y discriminación, el derecho a la libertad de pensamiento, conciencia, religión o convicciones. 25 de noviembre de 1981, R/36/55.

—. Declaración Universal de los Derechos Humanos. 10 de diciembre de 1948.

- Pacto Internacional de Derechos Económicos, Sociales y Culturales. 16 de diciembre de 1966, R/2200/A/XXI.

Peña Torres, Marisol. "La aplicación del Derecho Internacional de los Derechos Humanos por el Tribunal Constitucional Chileno". Estudios Constitucionales 8, n. ${ }^{\circ} 1$ (2010): 425-42. 〈http://www.estudiosconstitucionales.cl/index.php/econstitucionales〉.

Pierre, Bourdieu. “Algunas propiedades de los campos”. En Cuestiones de Sociología, 112-9. Madrid: Akal, 2008.

—. "Espacio social y poder simbólico". En Cosas dichas, 127-42. México: Gedisa, 2000.

—. "Estructuras, hábitos y prácticas". En El sentido práctico, 85-105. Buenos Aires: Siglo XXI Editores, 2007.

Scorsese, Martin. The Last Temptation of Christ. DVD. EE. UU.: Cineplex Odeon Films, 1988. 